IMPACT OF INTELLECTUAL PROPERTY RIGHTS ON THE GOVERNANCE

MODE DECISIONS OF ENGINEERING MANAGERS DURING THE

ESTABLISMENT OF RESEARCH ALLIANCES WITH PUBLICLY FUNDED

ENTITIES

Leonard Staphorst, South African National Research Network (SANReN), Council for Scientific and Industrial Research (CSIR); Mike Holland, Gordon Institute of Business Science, University of Pretoria; Leon Pretorius, Department of Engineering and Technology Management, University of Pretoria; Marthinus Willem Pretorius, Department of Engineering and Technology Management, University of Pretoria

\begin{abstract}
Strengthening Intellectual Property Rights (IPRs) for publicly financed research and development $(R \& D)$ ensures that research organisations maximise the full national value of the Intellectual Property (IP) that they generate, but potential negative spill over effects on the perceived value of a research alliance might deter an existing alliance partner from continued collaboration, or a potential alliance partner from future collaboration. This study, performed in 2010 within the context of a prominent South African research council, aimed to develop a Structural Equation Modelling (SEM) based Value-Mediation Governance (VMG) decision making model that will enable engineering managers at publicly financed R\&D organisations to select optimal governance mode structures for the research alliances they are establishing to grow their organisations' R\&D capabilities.
\end{abstract}

Key words: Intellectual Property Rights, Research Alliances, Value-Mediation Governance, Structural Equation Modelling

\title{
INTRODUCTION
}

Research alliances involving universities, government agencies/institutes and private firms have been growing in prevalence and in significance in most industrial nations (Hertzfeld, Link \& Vonortas, 2006). Pateli (2009) argued that, with the emergence of knowledge and network intensive economies, the decision for technology-based firms between "going it alone" or "collaborating" is influenced by several internal and external factors related to 
resource scarcity (Howarth, 1994), the complexity of the product and/or service offerings, risks associated with innovation in the macro environment and the need to pre-empt potential competitors (Kotabe \& Swan, 1995). Pateli (2009) postulated that the inherent uncertainty prevailing in technology-based industries may significantly affect the expectations of firms in terms of the future value of their alliances. This, in turn, may have a significant impact on their governance choice for alliances, ranging from joint ventures and minority equity alliances, to non-equity alliances, such as contractual arrangements (Pateli, 2009; Mukherjee, Gaur, Gaur \& Schmid, 2013).

During the past two decades, many countries have become more aware of the value of the Intellectual Property (IP) created by publicly financed research organisations (OECD, 2003). This awareness reflects the recognition by governments that, in many cases, placing the outputs of government financed research in the public domain is not sufficient to generate social and economic benefits (OECD, 2003). The United States (US) was first to create a legislative "solution" for this conundrum by enacting the Bayh-Dole Act in 1980 (Mowery \& Sampat, 2005). This Act encourages US universities to acquire patents on inventions resulting from government financed research, followed by issuing exclusive licenses to private firms (So, et al., 2008). Several countries followed suit by enacting similar legislation, with the latest followers being China, Brazil, Malaysia and South Africa (So, et al., 2008). Within the South African context, this has led to the 24 November 2008 enactment of the Technology Innovation Agency (TIA) Act (Republic of South Africa, 2008b) and the 22 December 2008 enactment of the Intellectual Property Rights from Publicly Financed Research and Development (IPRPFRD) Act (Republic of South Africa, 2008a).

It is now widely accepted that strong Intellectual Property Rights (IPRs) regimes promote the formation of inter-firm alliances (Oxley, 1999). Although strengthening IPRs for publicly financed Research and Development $(\mathrm{R} \& \mathrm{D})$ ensures that research organisations maximise the 
full national value of the IP that they generate, negative spill over effects that the legislation could incur on the perceived value of a research alliance might deter an existing alliance partner from continued collaboration, or a potential alliance partner from future collaboration. Hence, the perceived strength of such IPRs legislation can be viewed as a factor external to a research alliance and needs to be considered during the decision making process of strategically selecting an optimal research alliance governance model in order to maximise the perceived value of such a research alliance (Pateli, 2009).

The exploratory component of this study aimed to qualitative identification of potential impact domains within the South African legislative framework for IPR from publicly financed R\&D (consisting of the IPRPFRD and TIA Acts) that could potentially impact the perceived strength of the IPR regime and, hence, research alliance governance mode decisions taken by engineering managers. For example, preference might be given to an equity arrangement, such as a Research Joint Venture (RJV), over a purely contractual relationship. The confirmatory component of the study firstly involved the integration of the identified potential impact domains as indicators for the perceived strength of the IPRs regime within the Value-Mediation Governance (VMG) model originally proposed by Pateli (2009). Thereafter a quantitative verification of the modified VMG model was performed using Structural Equation Modelling (SEM) with Partial Least Squares (PLS) regression analysis within the context of the current and future research alliances at a prominent South African research council.

The contribution of the VMG model develop in this study to the practice of engineering management, is that it provides engineering managers at publicly funded organisations with a tool that can guide their partnering model decisions during the establishment of research alliances to grow their organisations' R\&D capabilities. Moreover, it will highlight to these 
engineering managers those partnering models that will not appeal to potential R\&D partners, as a function of the potential partners' perceived influence of the IPRPFRD and TIA Acts.

This paper is structured as follows: Firstly, a literature and theory review is presented on Research Alliances, Intellectual Property Rights and the influence of Intellectual Property Rights on Research Alliances. Next and overview is provided of the research objectives, question and hypotheses consider during this study. This is followed by a discussion of the research methodologies employed during this study. The results obtained are then presented and discussed. Lastly, concluding remarks are provided.

\section{LITERATURE AND THEORY REVIEW}

\section{Research Alliances}

According to Hertzfeld, et al. (2006) research alliances, also commonly referred to as research partnerships, are complex organisational arrangements that can assume numerous governance forms, ranging from infrastructure sharing, the sharing of information and knowledge, to the formation of entirely new research entities with equity sharing between alliance partners, such as RJVs (Hertzfeld, et al., 2006). Many arrangements include a large number of firms joining simply to define industry standards (Hertzfeld, et al., 2006). Most popular, however, are pure one-on-one research ventures (Hertzfeld, et al., 2006). In addition, there exists numerous product-focused alliances between research firms, customers and/or suppliers, aimed at solving a particular product or service related problem (Hertzfeld, et al., 2006). Contractual R\&D partnerships, such as joint $R \& D$ pacts and joint development agreements, are characterised by common R\&D activities of two or more firms, limited to a project or programme of finite duration (Hagedoorn, Cloodt and van Kranenburg, 2005).

Alliance governance, which is not only a crucial process during alliance creation, but also during alliance growth and evolution, primarily involves choosing between equity and non- 
equity structural forms on the alliance governance mode spectrum, depicted in Exhibit 1 (Pateli, 2009). On the one end of the alliance governance mode spectrum is equity alliances (also referred to as quasi-hierarchies), which include joint ventures and minority equity alliances (Pateli, 2009; Narula and Hagedoorn, 1999). On the other end of the spectrum is non-equity alliances (also referred to as quasi-markets), which include contractual arrangements that do not involve equity exchange (Pateli, 2009; Narula and Hagedoorn, 1999). Contractual agreements are further decomposed into the following categories, adapted from Pateli (2009): Once-off contracts that represent collaborative relationships that only exist during a single once-off project, recurrent contracts that represent collaborative relationships of short to moderate duration (Pateli, 2009) and relational contracts that represent a moderate to long-term social-embedded relationship (Wang and Wei, 2007).

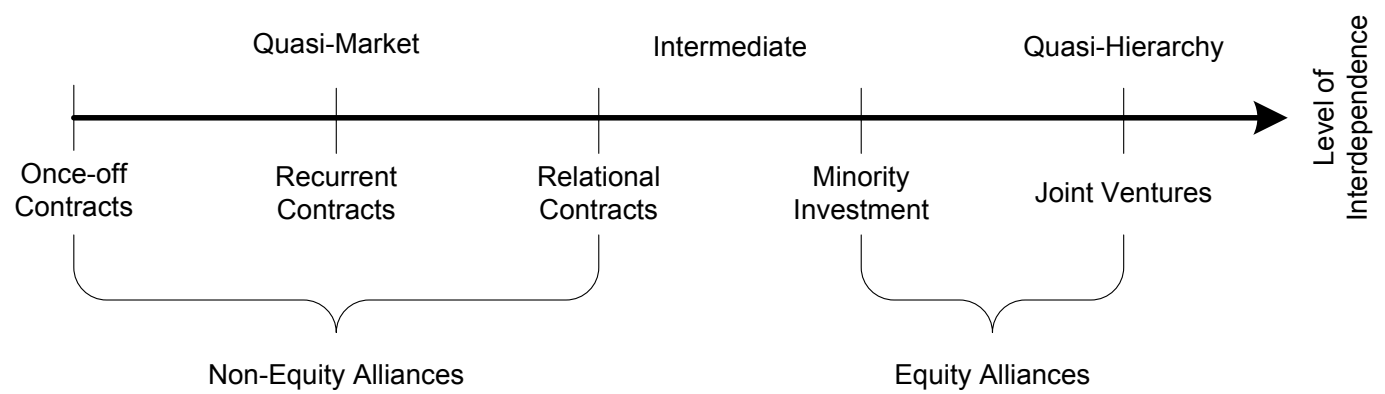

Exhibit 1: Alliance governance mode spectrum (adapted from Pateli (2009))

From a theoretical perspective, alliance governance has been modelled in the strategic management field using several alternative perspectives, with the most prevalent perspectives listed below (Pateli, 2009):

- Cost-Based Perspective: This perspective is embodied within the theory of Transaction Cost Economics (TCE), which proposes that governance choices are determined by the balance between efficiency and protection that each alliance 
partner anticipates to achieve from the alliance (Chen and Chen, 2003; Leiblein, 2003).

- Resource-Based Perspective: This perspective is grounded mainly in the Resourcebased View (RBV) of firms, which dictates that governance choices depends mainly on the type, amount, heterogeneity, and complementary characteristics of the resources exchanged/shared between alliance partners (Chen and Chen, 2003). Furthermore, the RBV model supports a governance structure that maintains balance between resource exchange ease and limiting unintended leakages (Oxley and Sampson, 2004).

- Value-Based Perspective: This perspective is based on the approach that valuecreation logic needs to be applied to the alliance governance mode decision (Leiblein, 2003). One theory that purports this perspective is that of Real Options Approach (ROA), which addresses environment uncertainty and its impact on the governance structure of an alliance by defining two possible value options, namely the "option to defer" and the "option to growth" (Leiblein, 2003).

\section{Value-Mediation Governance Model for Alliance Governance}

In 2009 Pateli proposed a VMG model for governance mode decision making at technologybased alliance (Pateli, 2009). Pateli's VMG model employs SEM with PLS regression to model and identify the potential interrelationship between internal uncertainty factors, external uncertainty factors, the expected value of the technology alliance and the preferred alliance governance mode selected by the alliance partners (Pateli, 2009). Based on Oxley's notation that the preferred alliance governance mode of a strategic alliance is related to the perceived strength of the IPRs regime within which the alliance operates (Oxley, 1999), the study added Perceived IPRs Regime Strength as an additional external uncertainty factor to 
Pateli's original VMG model (Pateli, 2009). Furthermore, the study postulated that Perceived IPRs Regime Strength is an exogenous latent construct, with research alliance related impact domains within the South African IPRPFRD and TIA Acts acting as potential formative indicators. In the modified VMG model (Pateli, 2009) depicted in Exhibit 2, internal uncertainty is estimated from alliance partner compatibility, the competitive relationship between partners, and alliance history. External uncertainty in the modified VMG model (Pateli, 2009) consists of competition intensity and environment uncertainty.

The VMG model also introduces the Expected Alliance Value (EAV) construct as a mediating factor on the relationships between uncertainty factors and the preferred alliance governance mode, which allows for the mitigation of the effects of either the current firm value, or the internal uncertainty related to the governance mode decision itself (Pateli, 2009). Rooted in the ROA, the EAV construct is defined as a multi-dimensional construct that attempts to measure the expected benefits incurred by an alliance partner firm from its participation in a strategic alliance (Pateli, 2009). It is based on the key assumption that value expectations are realised when alliance partners' objectives for the alliance formation are fulfilled (Pateli, 2009). 


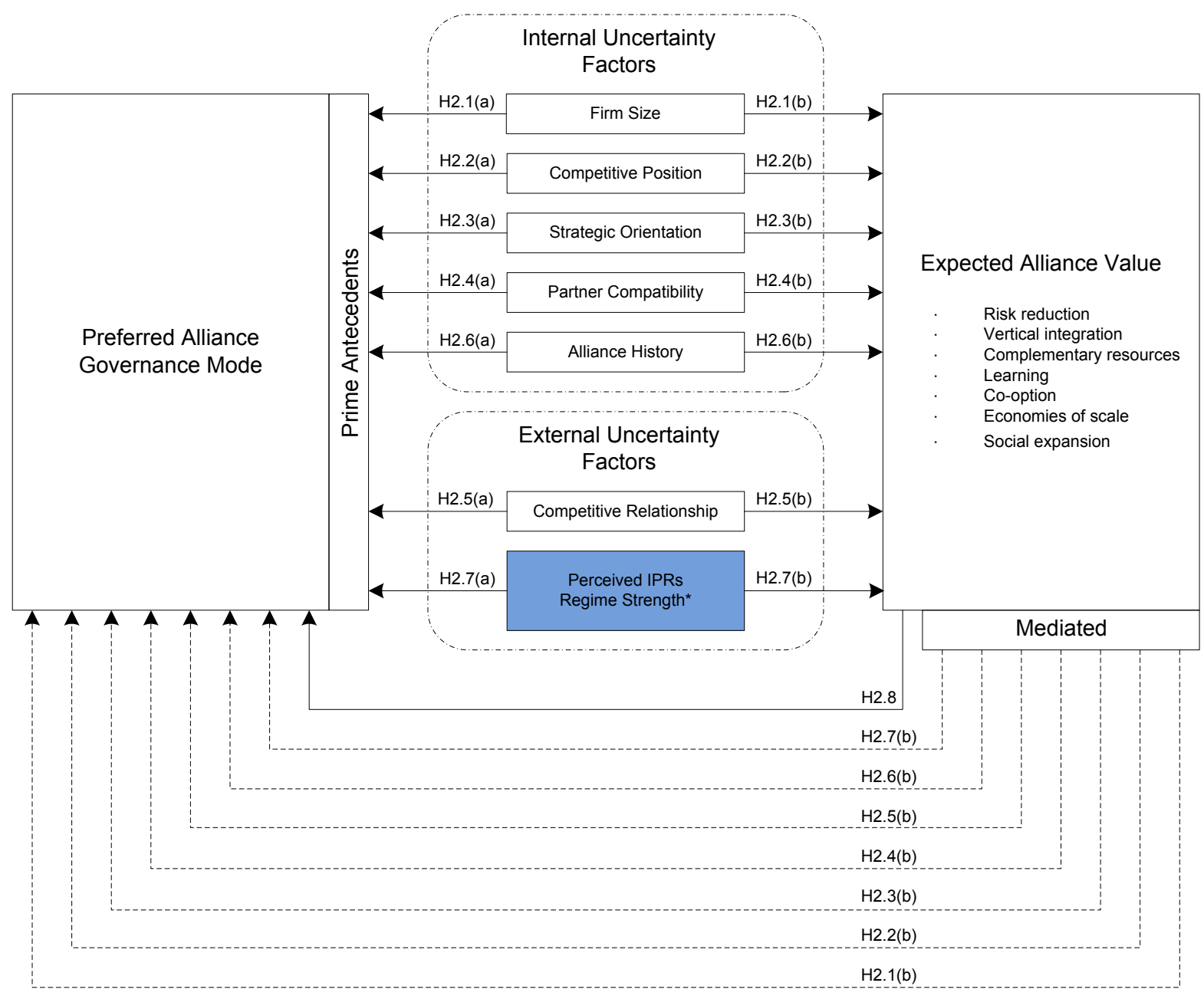

* External Uncertainty Factor Added by this Study

Exhibit 2: Modified VMG model (adapted from Pateli (2009))

\section{Intellectual Property Rights}

Core to the notion of a knowledge economy is the belief that the greatest level of economic efficiency occurs with the widest possible dissemination of new knowledge (Maredia, 2001). However, if everybody is free to access new knowledge, inventors and innovators have little incentive to commit resources, such as funding, human capital and production resources, to commercialise it. Hence, IPRs effectively transform knowledge from a public good into a private good, albeit for a limited time frame (Maredia, 2001). One can therefore argue that the enhanced market power conferred to the owners of IPRs not only enable them to recoup 
their expenditure in creating this new knowledge, but also creates incentive to engage in further invention and innovation.

Hertzfeld, Link and Vonortas (2001) claim that the use of Intellectual Property Protection Mechanisms (IPPMs) in research alliances depends on various factors, including the type of knowledge to be protected, the kind of competition in the specific industry, the organisational characteristics and culture of the owner of the knowledge, the governance structure of the alliance, the objectives of the partnership and the position of the alliance in the continuum from the early planning stage to termination. Hertzfeld, et al. (2006) investigated a large substantial set of large, diversified US firms that with regards to their assessment of the role and effectiveness of IPPMs in the formation and implementation of research alliances. Their research confirms that resolving issues related to IPR protection is a fundamental consideration for all research alliance partners involved (Hertzfeld, et al. 2006).

The Bayh-Dole Act (Mowery and Sampat, 2005) was implemented in 1980 in the US with the primary intent to promote the growth of technology-based small businesses by allowing them to own the patents that were produced out of federally sponsored research. The Act defined that universities and other small entities would not develop their patented technologies themselves, but would rather license the patents to industry for development and commercialisation. Furthermore, a provision of the Act allowed for the university retention of royalties to be reinvested into its research and educational activities), as well as specifying that a fraction of the royalties received need to be allocated as personal income to the inventors (So, et al., 2008). Recently, legislation emulating the US Bayh-Dole Act has been created in countries such as China, Brazil, Malaysia, India and South Africa (So, et al., 2008). In 2008 the South African government has recently implemented a legislative attempt to strengthen IPR protection for publicly financed R\&D by means of the IPRPFRD Act, as well as the establishment of the TIA (Baloyi, et al., 2009). The primary purpose of the IPRPFRD 
Act is to provide legislative mechanisms to protect IP emanating from publicly financed R\&D by requiring that it be identified, protected, utilised and commercialised for the advantage of the people of South Africa, whether it be for a social, economic, military or any other benefit (Baloyi, et al., 2009). The TIA Act established the TIA, which is designed to stimulate the development of technology-based products and services, stimulate the development of public and private sector technology-based enterprises, develop a significant technology base for the South African economy, facilitate the development of human capital for innovation and provide the primary bridge between the formal knowledge base and the real economy.

Baloyi, et al. (2009) performed a qualitative exploratory study to identify potential impact domains of the IPRPFRD and TIA Acts within the context of the considered research council's operational processes, infrastructure and resources. Baloyi, et al. (2009) identified eight domains of potential business impact within the research council, which include: IP detection process, IP declaration process, benefit sharing policies, offshore IP registration process, government reporting process, government publication approval process, government reaction time and the structural and resource requirements to support the Acts.

\section{RESEARCH OBJECTIVES, QUESTIONS AND HYPOTHESES}

The first research objective of this study entailed identifying the three most significant impact domains within the Acts which influence governance mode decisions for research alliances within the context of the research council's research alliance network. The following research questions were addressed as part of Research Objective 1:

- Research Question 1.1: Which domains within the Acts could be used as formative indicators for the perceived strength of the South African publicly financed IPRs regime? 
- Research Question 1.2: Which three of the impact domains within the Acts could most significantly impact governance mode decisions within research alliances by acting as formative indicators for the perceived strength of the IPRs regime?

The second research objective aimed to incorporate Phase 1's three identified impact domains into the VMG model (Pateli, 2009) as formative indicators for the Perceived IPRs Regime Strength external uncertainty factor. Furthermore, the following Research Propositions were adapted from Pateli (2009) in order to quantitatively evaluate the validity of the modified VMG model within context of the current and potential research alliance network of the research council:

- Research Proposition H2.1(a): The preference for quasi-hierarchy governance modes is positively related to partner firm size.

- Research Proposition H2.1(b): The relationship between partner firm size and the preference for quasi-hierarchy governance modes is mediated via the EAV.

- Research Proposition H2.2(a): The preference for quasi-hierarchy governance modes is positively related to strength of the alliance partner firm's competitive position.

- Research Proposition H2.2(b): The relationship between the strength of the alliance partner firm's competitive position and the preference for quasi-hierarchy governance modes is mediated via the EAV.

- Research Proposition H2.3(a): The preference for quasi-hierarchy governance modes is positively related to the increased importance of growth.

- Research Proposition H2.3(b): The relationship between the increased importance of growth strategies and the preference for quasi-hierarchy governance modes is mediated via the EAV. 
- Research Proposition H2.4(a): The preference for quasi-hierarchy governance modes is positively related to increased partner compatibility.

- Research Proposition H2.4(b): The relationship between increased partner compatibility and the preference for quasi-hierarchy governance modes is mediated via the EAV.

- Research Proposition H2.5(a): The preference for quasi-hierarchy governance modes is positively related to intensity in the partner competitive relationship.

- Research Proposition H2.5(b): The relationship between the intensity in the partner competitive relationship and the preference for quasi-hierarchy governance modes is mediated via the EAV.

- Research Proposition H2.6(a): The preference for quasi-hierarchy governance modes is positively related to the alliance history of the partners.

- Research Proposition H2.6(b): The relationship between the alliance history of the partners and the preference for quasi-hierarchy governance modes is mediated via the EAV.

- Research Proposition 2.7(a): The preference for quasi-hierarchy governance modes is positively related to the perceived strength of the IPRs regime within which the research alliance operates.

- Research Proposition 2.7(b): The relationship between the perceived strength of the IPRs regime within which the research alliance operates and the preference for quasihierarchy governance modes is mediated via the EAV.

- Research Proposition H2.8: The preference for quasi-hierarchy governance modes is positively related to high expectations for EAV. 


\section{RESEARCH METHODOLOGY}

\section{Populations and Units of Analysis}

This study was conducted in two distinct phases. Phase 1 addressed Research Objective 1, while Phase 2 addressed Research Objective 2. Phase 1 and Phase 2 had identical populations and units of analysis. The unit of analysis (Zikmund, 2003) was an existing or future research alliance of the research council that is impacted by the South African IPRs legislative framework for publicly financed R\&D. The population (Zikmund, 2003) consisted of all existing and future research alliances, with governance structures spanning all possibilities in a spectrum ranging from non-equity to equity, where one or more of the partners is a publicly financed South African government R\&D research institute or university and one or more of the partners is a private sector firm that receives funding for $R \& D$ activities from the South African government.

\section{Sampling Frames, Plans and Size Requirements}

The sampling frame (Zikmund, 2003) for Phase 1 consisted of all engineering managers of the various business units within the research council. As low response rate was expected for this qualitative research phase of the study, it was decided to distribute the online survey to all 36 engineering managers within the research council. Phase 2's sampling frame consisting of all of the research council's current and potential research alliance partners. A representative sample of alliance partners was created using submissions from Phase 1's engineering managers. Since these engineering managers submitted contact information for their respective current and future research alliance partners on a discretionary bases, the sampling plan for this phase can be described as stratified sampling, with the strata selected consisting of the 36 business units within the research council. Sampling within these strata consisted of convenience sampling (Zikmund, 2003). Using the "10-times-rule" defined by 
Goodhue, Lewis and Thompson (2006) for SEM with PLS-based regression, this phase required a response rate of at least 30 alliance partners.

\section{Research Instruments}

Data collection for Phase 1 of the research project utilised a Google Forms (Google, 2010) online self-administered survey (Zikmund, 2003). As this phase of the study was qualitative in nature, this questionnaire contained only open-ended questions. It was augmented with the support of a survey companion website that succinctly explained the contents of the IPRPFRD and TIA Acts.

A Google Forms (Google, 2010) online self-administered survey (Zikmund, 2003) constituted the research instrument for Phase 2 of the study. The survey was based on Pateli's questionnaire (Pateli, 2009), with slight modifications in wording for improved readability. Items were also added in order to accommodate the Perceived IPRs Regime Strength external uncertainty factor, with statements for each of the three IPR impact domains identified during Phase 1 of the study acting as formative indicators.

\section{Data Analysis Methods}

Narrative inquiry (Clandinin and Connelly, 2000) was used to scrutinize responses to the Phase 1 questionnaire for common themes relating to potential domains within the IPRPFRD and TIA Acts that were perceived to impact governance mode decisions related to research alliances at the research council via their influence on the perceived strength of the IPRs regime. Constant comparative method (Glasser, 1965) was then used to compare the eight business impact areas previously identified within the IPRPFRD and TIA Acts by Baloyi, et al. (2009) to the themes identified using Narrative Inquiry in order to create an updated list of impact domain areas. Lastly, frequency analysis (Zikmund, 2003) was used to determine the weighted frequency of occurrence (with weighting based on severity level) with which the 
impact domains identified in the IPRs legislative framework were cited as having an impact on governance mode decisions for the research alliances of the respondents' business units. From this weighted frequency analysis the three highest impact domains were then identified and used in Phase 2 as formative indicators for the Perceived IPRs Regime Strength (Oxley, 1999) external uncertainty factor in the modified VMG model (Pateli, 2009).

Using these schematic and symbol conventions proposed by Haenlein and Kaplan (2004), the SEM path diagram shown in Exhibit 3 was created, representing the modified VMG model (Pateli, 2009). PLS regression (Abdi, 2010; Vinzi, et al., 2010) was employed In order to determine the strength of the relationships between the uncertainty factors driving governance mode decision making and the preferred alliance governance mode, as defined by research propositions $\mathrm{H} 2.1$ (a) through $\mathrm{H} 2.6$ (a) for Research Objective 1. In order to evaluate the direct mediating effects that EAV has on the relationships between these uncertainty factors and the Preferred Alliance Governance Mode construct, Research Propositions H2.1(b) through H2.7(b) were tested using four step process proposed by Baron and Kenny (1986). 


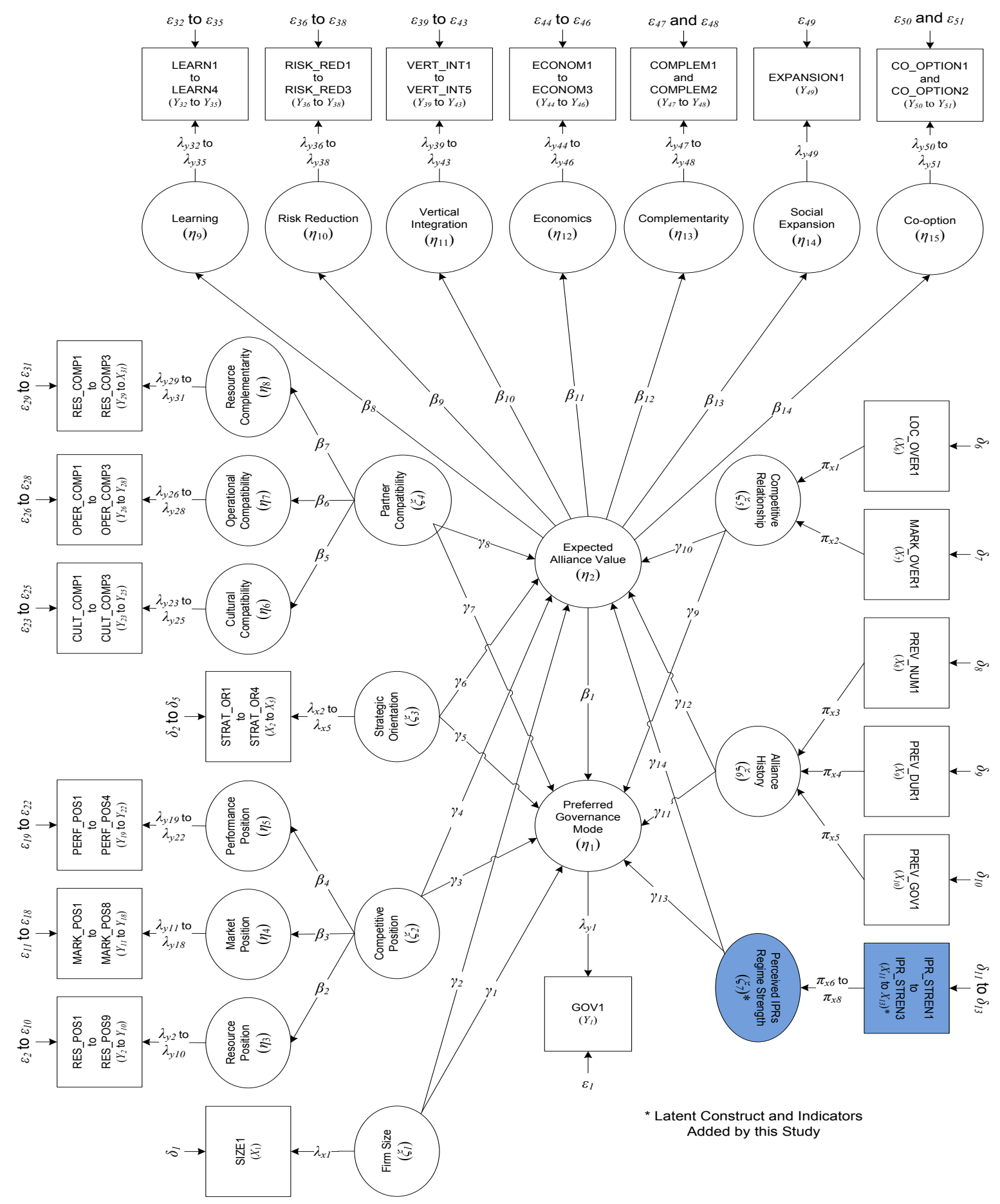

Exhibit 3: SEM path diagram for the modified VMG model

The PLS regression process involved the determination and evaluation of the loadings and path coefficients in the SEM path diagram for the modified VMG model (Pateli, 2009). The freeware software package SmartPLS (Ringle, Wende and Will, 2010) was employed to realise the VMG model's (Pateli, 2009) SEM path diagram and calculate all loadings and 
path coefficients through PLS regression. SmartPLS was configured to normalise all measured survey items (Ringle, et al., 2010), as a variety of scaling approaches and ranges was used in Phase 2's survey. SmartPLS was also used to evaluate the reliability and validity test criteria.

\section{Testing for Reliability and Validity}

Reliability and validity for Phase 1 of the study was tested using the methodological triangulation approach. This involved comparing the online survey responses of one of the business unit's engineering managers with the responses captured via an in-depth interview during which the same questions were posed.

To evaluate the reliability and validity of the measurement portion of the SEM for the modified VMG model (Pateli, 2009), this study employed the following tests (Vinzi, et al., 2010): Indicator Reliability, Construct Reliability and Convergent Validity. This was then followed by the following test to evaluate the reliability and validity of the structural portion: Coefficients of Determination, Path Coefficient Significance and Predictive Validity.

\section{Research Limitations}

The following potential limitations have been identified for this study:

- By performing Phase 2 of the study using the research council's current and potential research alliance partners as respondent base, the research council's own view is not reflected in the collected data, thereby limiting the modified VMG model (Pateli, 2009) to only predict or explain the governance mode decision making of their current and potential research alliance partners, and not that of the research council itself.

- By limiting the sampling plans of the study to the research council and its current and potential research alliance partners, the results that were obtained cannot be blindly 
generalised to a larger population consisting of all South African publicly financed R\&D institutions and their current and potential research alliance partners.

\section{RESULTS}

\section{Results for Phase 1}

A total of $N=10$ engineering managers, spread across the various operational units of the research council, responded to Phase 1's online qualitative survey. Application of Theme Extraction and Constant Comparative Method analysis to these responses confirmed the sufficiency of this sample size, since data saturation (Guest, et al., 2006) for the extracted themes, representing potential impact domains within the Acts that could influence research alliances, had already occurred when the fifth response was captured.

\section{Results for Research Question 1.1}

Narrative Inquiry in the form of Theme Extraction, combined with Constant Comparative Method (using as baseline the eight business impact domains identified by Baloyi, et al. (2009) in the Acts), was used to extract the impact domains listed in Exhibit 4 for each of the 10 responses received to Phase 1's survey. The perceived severity of the impact domains listed by each respondent is also indicated in this. Merging all unique themes listed in Exhibit 4 with the potential business impact domains identified by Baloyi, et al. (2009) produced the updated list of 13 potential business impact domains shown in Exhibit 5.

Exhibit 4: Themes extracted from responses to Phase 1's survey

\begin{tabular}{|l|l|}
\hline Respondent & Impact Domains Identified with Extracted Severity Levels \\
\hline 1 & $\begin{array}{l}\text { 1. Requirement for non-exclusivity in IP transactions (Severity = Low) } \\
\text { 2. Choice of IPRs ownership (Severity = Low) }\end{array}$ \\
\hline
\end{tabular}




\begin{tabular}{|c|c|}
\hline 2 & $\begin{array}{l}\text { 1. Requirement to register IP in the OpenSource software community (Severity } \\
\text { = Medium) } \\
\text { 2. Requirement for non-exclusivity in IP transactions (Severity = Medium) }\end{array}$ \\
\hline 3 & $\begin{array}{l}\text { 1. IP declaration process }(\text { Severity }=\text { High }) \\
\text { 2. Benefit sharing policies (Severity }=\text { High) } \\
\text { 3. Offshore IP registration process (Severity }=\text { High) } \\
\text { 4. State walk-in rights on IP not declared (Severity }=\text { High) } \\
\text { 5. Preference in commercialisation rights to Small or Medium Enterprises } \\
(\text { SMEs) and BBBEE firms (Severity }=\text { High) } \\
\text { 6. IP detection process (Severity }=\text { High) }\end{array}$ \\
\hline 4 & $\begin{array}{l}\text { 1. Choice of IPRs ownership (Severity }=\text { High) } \\
\text { 2. Unclear guidelines for the TIA funding of innovations (Severity = Medium) }\end{array}$ \\
\hline 5 & $\begin{array}{l}\text { 1. Government reporting process }(\text { Severity }=\text { Medium) } \\
\text { 2. Government reaction time (Severity }=\text { Medium) } \\
\text { 3. Benefit sharing policies (Severity }=\text { Medium) } \\
\text { 4. State walk-in rights on IP not declared (Severity }=\text { High) } \\
\text { 5. Requirement to register IP in the OpenSource software community (Severity } \\
=\text { Medium) } \\
\text { 6. Offshore IP registration process (Severity }=\text { Medium) } \\
\text { 7. Structural and resource requirements (Severity }=\text { Medium) }\end{array}$ \\
\hline 6 & $\begin{array}{l}\text { 1. Choice of IPRs ownership (Severity }=\text { High) } \\
\text { 2. Government reporting process (Severity }=\text { High) } \\
\text { 3. Government reaction time (Severity }=\text { Medium) } \\
\text { 4. Benefit sharing policies (Severity }=\text { High) } \\
\text { 5. State walk-in rights on IP not declared (Severity }=\text { High) }\end{array}$ \\
\hline
\end{tabular}




\begin{tabular}{|l|l|}
\hline 7 & $\begin{array}{l}\text { 1. Choice of IPRs ownership (Severity }=\text { High) } \\
\text { 2. Benefit sharing policies (Severity }=\text { High) } \\
\text { 3. Requirement for non-exclusivity in IP transactions (Severity }=\text { High) } \\
\text { 4. State walk-in rights on IP not declared (Severity }=\text { High) }\end{array}$ \\
\hline 8 & $\begin{array}{l}\text { 1. IP detection process (Severity }=\text { Medium) } \\
\text { 2. Requirement to register IP in the OpenSource software community (Severity }\end{array}$ \\
\hline 9 & $\begin{array}{l}\text { 1. Choice of IPRs ownership (Severity }=\text { Medium) } \\
\text { 2. Offshore IP registration process (Severity }=\text { Medium) } \\
=\text { High) } \\
\text { 2. Preference in commercialisation rights to SMEs and BBBEE firms (Severity } \\
=\text { High) }\end{array}$ \\
\hline 10 &
\end{tabular}

Exhibit 5: Updated list of potential business impact domains

\begin{tabular}{|l|l|}
\hline Theme Identified & Theme Description \\
\hline Choice of IPRs ownership & $\begin{array}{l}\text { A public sector R\&D organisation can choose the ownership of } \\
\text { the IPRs obtained for IP it had generated from partial or full } \\
\text { government financing. }\end{array}$ \\
\hline State walk-in rights on IP & The State is granted walk-in rights on the IPR obtained for IP \\
that was generated through public financing, but was not \\
properly declared to government. \\
\hline Benefit sharing policies & As described by Baloyi, et al. (2009). \\
\hline Requirement to register IP & Publicly financed R\&D projects that could generate IP during \\
\hline
\end{tabular}




\begin{tabular}{|c|c|}
\hline $\begin{array}{l}\text { in the OpenSource } \\
\text { software community }\end{array}$ & $\begin{array}{l}\text { the development of software within the OpenSource community, } \\
\text { will have to be approved by government. }\end{array}$ \\
\hline $\begin{array}{l}\text { Offshore IP registration } \\
\text { process }\end{array}$ & As described by Baloyi, et al. (2009). \\
\hline $\begin{array}{l}\text { Requirement for non- } \\
\text { exclusivity in IP } \\
\text { transactions }\end{array}$ & $\begin{array}{l}\text { In transactions where IP is licensed to entities in order to } \\
\text { pursue commercialisation, preference needs to be given to non- } \\
\text { exclusive deals. }\end{array}$ \\
\hline $\begin{array}{l}\text { Preference in } \\
\text { commercialisation rights to } \\
\text { SMEs and BBBEE firms }\end{array}$ & $\begin{array}{l}\text { Within the broad requirement for non-exclusive deals, } \\
\text { preference needs to be given to South African SMEs and } \\
\text { BBBEE accredited firms. If IP holders are not able to license } \\
\text { the IP within this framework, evidence to this effect needs to be } \\
\text { submitted to government for approval. }\end{array}$ \\
\hline IP detection process & As described by Baloyi, et al. (2009). \\
\hline $\begin{array}{l}\text { Government reporting } \\
\text { process }\end{array}$ & As described by Baloyi, et al. (2009). \\
\hline Government reaction time & As described by Baloyi, et al. (2009). \\
\hline IP declaration process & As described by Baloyi, et al. (2009). \\
\hline $\begin{array}{l}\text { Structural and resource } \\
\text { requirements }\end{array}$ & As described by Baloyi, et al. (2009). \\
\hline $\begin{array}{l}\text { Unclear guidelines for the } \\
\text { TIA funding of innovations }\end{array}$ & As described by Baloyi, et al. (2009). \\
\hline $\begin{array}{l}\text { Government publication } \\
\text { approval process }\end{array}$ & As described by Baloyi, et al. (2009). \\
\hline
\end{tabular}




\section{Results for Research Question 1.2}

An analysis of the responses to Question B.2 of Phase 2's survey was used to determine the perceived severity of the impact domains identified by each respondent. For instances where responses to this survey question did not explicitly indicate the perceived level of severity, a severity level of Medium was selected. The severity levels for the identified impact domains were encoded as High $=3$, Medium $=2$ and Low $=1$. Weightings for each identified impact domain were then summed to obtain a cumulative weighting. Based on this cumulative weighting the impact domains given in were then ranked in a descending order as shown in Exhibit 6.

Exhibit 6: Ranking of extracted impact domains according to perceived severity

\begin{tabular}{|l|l|l|}
\hline Theme Identified & Cumulative & Severity \\
& Weighting & Ranking \\
\hline Choice of IPRs ownership & 12 & 1 \\
\hline State walk-in rights on IP not declared & 12 & 1 \\
\hline Benefit sharing policies & 11 & 2 \\
\hline Requirement to register IP in the OpenSource software & 9 & 3 \\
\hline community & 7 & 4 \\
\hline Offshore IP registration process & 7 & 5 \\
\hline Requirement for non-exclusivity in IP transactions & 6 & 6 \\
\hline Preference in commercialisation rights to SMEs and & 6 & 6 \\
\hline BBBEE firms & & \\
\hline IP detection process & 5 & \\
\hline Government reporting process & 5 & \\
\hline
\end{tabular}




\begin{tabular}{|l|l|l|}
\hline Government reaction time & 4 & 7 \\
\hline IP declaration process & 3 & 8 \\
\hline Structural and resource requirements & 2 & 9 \\
\hline Unclear guidelines for the TIA funding of innovations & 2 & 9 \\
\hline Government publication approval process & 0 & 10 \\
\hline
\end{tabular}

From this ranked list of impact domains the following three highest ranked impact domains were selected as formative indicators for the Perceived IPRs Regime Strength (Oxley, 1999; Dinopoulos \& Segerstrom, 2010) construct in the modified VMG model (Pateli, 2009): Choice of IPRs ownership, State walk-in rights on IP not declared and Benefit sharing policies.

\section{Reliability and Validity for Phase 1}

By means of the methodological triangulation approach used to test for the reliability and validity for Phase 1 of the study it was determined that the responses captured via the indepth interview and the online survey from the selected engineering manager were highly correlated. Hence, it is safe to assume an acceptable level of reliability and validity was achieved during Phase 1.

\section{Results for Phase 2}

A total of $N=62$ responses were received for the Phase 2 online quantitative survey sent to a sample consisting of 171 current and potential research alliance partners of the research council. The population definition for Phase 2 encompassed both current research alliances, as well as potential research alliances with the research council. Responses to related to measurement indicator PREV_PAST1 in the online survey for Phase 2, which tested for the 
presence of past research alliances with the research council, were used to categorise respondents as part of subpopulations consisting of either current research alliance partners, or potential research alliance partners. From these descriptive statistics for the nominal scaled items in Phase 2's survey it was observed that $90.32 \%$ of respondents represented organisations that were located in South Africa, while only 6.45\% represented a South African government financed R\&D organisation similar to the research council.

Descriptive statistics for the ordinal-scaled items in Phase 2's survey highlighted that $40 \%$ of respondents rated relational contracts as their most preferred governance mode for research alliances with publicly financed $R \& D$ organisation, making this the dominant governance mode choice. With reference to the three impact domains identified during Phase 1 as potential formative indicators for the Perceived IPRs Regime Strength construct, both the choice of the ownership of IPRs and the requirement for benefit-sharing policies received dominant ratings of 5 (selected by $26 \%$ and $29 \%$ of the respondents for the former and the latter impact domains, respectively), while state walk-in rights on undeclared IP received a neutral rating (selected by $22 \%$ of the respondents).

\section{PLS Regression SEM Results for Phase 2}

Reporting of the PLS regression results of the SEM for the modified VMG is based on the proposed reporting standard defined by Vinzi, et al. (2010). According to this reporting standard, the PLS regression results for the measurement portion of the SEM path diagram, consisting of the loadings for all of the measurement indicators in the model, are reported first, followed by the PLS regression results for the structural portion of the SEM path diagram, consisting of the path coefficients for all interrelationships between constructs.

The measurement indicator loadings for the measurement portion of the SEM for the modified VMG model (Pateli, 2009) are listed in Exhibit 7. Although these loadings were not 
used directly in order to evaluate the research propositions for Research Objective 2, a detailed investigation thereof was crucial in order to determine those reflective indicators that did not comply with the minimum Indicator Reliability level of 0.4 . The results given in Exhibit 7 constitute the final indicator loadings, determined following the removal of seven unreliable reflective indicators, which resulted in improved Construct Reliability for their associated latent constructs.

Exhibit 7: Measurement portion SEM loading results

\begin{tabular}{|c|c|c|c|}
\hline Constructs & Indicator Type & Indicators & Loadings \\
\hline Firm Size $\left(\xi_{1}\right)$ & Reflective & SIZE1 $\left(X_{1}\right)$ & $\lambda_{x 1}=1.000$ \\
\hline \multirow[t]{4}{*}{ Strategic Orientation $\left(\xi_{3}\right)$} & \multirow[t]{4}{*}{ Reflective } & STRAT_ORI $\left(X_{2}\right)$ & $\lambda_{x 2}=0.892$ \\
\hline & & STRAT_OR2 $\left(X_{3}\right)$ & $\lambda_{x 3}=0.708$ \\
\hline & & STRAT_OR3 $\left(X_{4}\right)$ & $\lambda_{x 4}=0.644$ \\
\hline & & STRAT_OR4 $\left(X_{5}\right)$ & Excluded \\
\hline \multirow[t]{2}{*}{ Competitive Relationship $\left(\xi_{5}\right)$} & \multirow[t]{2}{*}{ Formative } & LOC_OVERI $\left(X_{6}\right)$ & $\pi_{x l}=0.029$ \\
\hline & & $\begin{array}{l}\text { MARK_OVERI } \\
\left(X_{7}\right)\end{array}$ & $\pi_{x 2}=0.923$ \\
\hline \multirow[t]{3}{*}{ Alliance History $\left(\xi_{6}\right)$} & \multirow[t]{3}{*}{ Formative } & PREV_NUMI $\left(X_{8}\right)$ & $\pi_{x 3}=0.601$ \\
\hline & & PREV_DURI $\left(X_{9}\right)$ & $\pi_{x 4}=0.318$ \\
\hline & & PREV_GOV1 $\left(X_{10}\right)$ & $\pi_{x 5}=0.954$ \\
\hline \multirow[t]{3}{*}{ Perceived IPRs Regime Strength $\left(\xi_{7}\right)$} & \multirow[t]{3}{*}{ Formative } & IPR_STREN1 $\left(X_{11}\right)$ & $\pi_{x 6}=0.779$ \\
\hline & & IPR_STRENI $\left(X_{12}\right)$ & $\pi_{x 7}=0.591$ \\
\hline & & IPR_STREN3 $\left(X_{13}\right)$ & $\pi_{x 8}=0.906$ \\
\hline
\end{tabular}




\begin{tabular}{|c|c|c|c|}
\hline $\begin{array}{l}\text { Preferred Alliance Governance Mode } \\
\left(\eta_{1}\right)\end{array}$ & Reflective & GOV1 $\left(Y_{1}\right)$ & $\lambda_{y 1}=1.000$ \\
\hline \multirow[t]{9}{*}{ Resource Position $\left(\eta_{3}\right)$} & \multirow[t]{9}{*}{ Reflective } & RES_POS1 $\left(Y_{2}\right)$ & $\lambda_{y 2}=0.635$ \\
\hline & & $R E S \_P O S 2\left(Y_{3}\right)$ & $\lambda_{y 3}=0.692$ \\
\hline & & $R E S \_P O S 3\left(Y_{4}\right)$ & $\lambda_{y 4}=0.657$ \\
\hline & & RES_POS4 $\left(Y_{5}\right)$ & $\lambda_{y 5}=0.776$ \\
\hline & & RES_POS5 $\left(Y_{6}\right)$ & $\lambda_{y 6}=0.646$ \\
\hline & & RES_POS6 $\left(Y_{7}\right)$ & $\lambda_{y 7}=0.737$ \\
\hline & & $R E S \_P O S 7\left(Y_{8}\right)$ & $\lambda_{y 8}=0.705$ \\
\hline & & RES_POS8 $\left(Y_{9}\right)$ & $\lambda_{y 9}=0.686$ \\
\hline & & RES_POS9 $\left(Y_{10}\right)$ & $\lambda_{y 10}=0.782$ \\
\hline \multirow[t]{8}{*}{ Market Position $\left(\eta_{4}\right)$} & \multirow[t]{8}{*}{ Reflective } & MARK_POS1 $\left(Y_{11}\right)$ & Excluded \\
\hline & & $M A R K \_P O S 2\left(Y_{12}\right)$ & Excluded \\
\hline & & $M A R K \_P O S 3\left(Y_{13}\right)$ & $\lambda_{y 13}=0.794$ \\
\hline & & MARK_POS4 $\left(Y_{14}\right)$ & Excluded \\
\hline & & MARK_POS5 $\left(Y_{15}\right)$ & $\lambda_{y 15}=0.845$ \\
\hline & & MARK_POS6 $\left(Y_{16}\right)$ & $\lambda_{y 16}=0.766$ \\
\hline & & $M A R K \_P O S 7\left(Y_{17}\right)$ & Excluded \\
\hline & & MARK_POS8 $\left(Y_{18}\right)$ & $\lambda_{y 18}=0.633$ \\
\hline \multirow[t]{2}{*}{ Performance Position $\left(\eta_{5}\right)$} & \multirow[t]{2}{*}{ Reflective } & PERF_POS1 $\left(Y_{19}\right)$ & $\lambda_{y 19}=0.758$ \\
\hline & & PERF_POS1 $\left(Y_{20}\right)$ & $\lambda_{y 20}=0.779$ \\
\hline
\end{tabular}




\begin{tabular}{|c|c|c|c|}
\hline & & PERF_POS3 $\left(Y_{21}\right)$ & $\lambda_{y 21}=0.772$ \\
\hline & & PERF_POS4 $\left(Y_{22}\right)$ & $\lambda_{y 22}=0.783$ \\
\hline \multirow[t]{3}{*}{ Cultural Compatibility $\left(\eta_{6}\right)$} & \multirow[t]{3}{*}{ Reflective } & $\begin{array}{l}\text { CULT_COMP1 } \\
\left(Y_{23}\right)\end{array}$ & $\lambda_{y 23}=0.839$ \\
\hline & & $\begin{array}{l}\text { CULT_COMP2 } \\
\left(Y_{24}\right)\end{array}$ & $\lambda_{y 24}=0.826$ \\
\hline & & $\begin{array}{l}\text { CULT_COMP3 } \\
\left(Y_{25}\right)\end{array}$ & $\lambda_{y 25}=0.462$ \\
\hline \multirow[t]{3}{*}{ Operational Compatibility $\left(\eta_{7}\right)$} & \multirow[t]{3}{*}{ Reflective } & $\begin{array}{l}\text { OPER_COMP1 } \\
\left(Y_{26}\right)\end{array}$ & $\lambda_{y 26}=0.851$ \\
\hline & & $\begin{array}{l}\text { OPER_COMP2 } \\
\left(Y_{27}\right)\end{array}$ & $\lambda_{y 27}=0.805$ \\
\hline & & $\begin{array}{l}\text { OPER_COMP3 } \\
\left(Y_{28}\right)\end{array}$ & Excluded \\
\hline \multirow[t]{3}{*}{ Resource Complementarity $\left(\eta_{8}\right)$} & \multirow[t]{3}{*}{ Reflective } & $R E S \_C O M P 1\left(Y_{29}\right)$ & $\lambda_{y 29}=0.803$ \\
\hline & & RES_COMP2 $\left(Y_{30}\right)$ & $\lambda_{y 30}=0.903$ \\
\hline & & $R E S \_C O M P 3\left(Y_{31}\right)$ & $\lambda_{y 31}=0.834$ \\
\hline \multirow[t]{4}{*}{ Learning $\left(\eta_{9}\right)$} & \multirow[t]{4}{*}{ Reflective } & LEARN1 (Y $\left.Y_{32}\right)$ & $\lambda_{y 32}=0.856$ \\
\hline & & $\operatorname{LEARN2}\left(Y_{33}\right)$ & $\lambda_{y 33}=0.866$ \\
\hline & & $\operatorname{LEARN3}\left(Y_{34}\right)$ & $\lambda_{y 34}=0.841$ \\
\hline & & LEARN4 $\left(Y_{35}\right)$ & $\lambda_{y 35}=0.976$ \\
\hline Risk Reduction ( $\left.\eta_{10}\right)$ & Reflective & $R I S K_{-} R E D 1\left(Y_{36}\right)$ & $\lambda_{y 36}=0.871$ \\
\hline
\end{tabular}




\begin{tabular}{|c|c|c|c|}
\hline & & $R I S K \_R E D 2\left(Y_{37}\right)$ & $\lambda_{y 37}=0.893$ \\
\hline & & $R I S K \_R E D 3\left(Y_{38}\right)$ & $\lambda_{y 38}=0.890$ \\
\hline Vertical Integration $\left(\eta_{11}\right)$ & Reflective & VERT_INTI $\left(Y_{39}\right)$ & $\lambda_{y 39}=0.847$ \\
\hline & & VERT_INT2 $\left(Y_{40}\right)$ & $\lambda_{y 40}=0.764$ \\
\hline & & VERT_INT3 $\left(Y_{41}\right)$ & $\lambda_{y 41}=0.662$ \\
\hline & & $V E R T \_I N T 4\left(Y_{42}\right)$ & Excluded \\
\hline & & VERT_INT5 $\left(Y_{43}\right)$ & $\lambda_{y 43}=0.743$ \\
\hline Economics $\left(\eta_{12}\right)$ & Reflective & ECONOM1 $\left(Y_{44}\right)$ & $\lambda_{y 44}=0.834$ \\
\hline & & ECONOM2 $\left(Y_{45}\right)$ & $\lambda_{y 45}=0.859$ \\
\hline & & $\operatorname{ECONOM3}\left(Y_{46}\right)$ & $\lambda_{y 46}=0.735$ \\
\hline Complementarity $\left(\eta_{13}\right)$ & Reflective & COMPLEM1 $\left(Y_{47}\right)$ & $\lambda_{y 47}=0.906$ \\
\hline & & COMPLEM2 $\left(Y_{48}\right)$ & $\lambda_{y 48}=0.931$ \\
\hline Social Expansion ( $\left.\eta_{14}\right)$ & Reflective & $\begin{array}{l}\text { EXPANSION1 } \\
\left(Y_{49}\right)\end{array}$ & $\lambda_{y 49}=1.000$ \\
\hline Co-option $\left(\eta_{15}\right)$ & Reflective & $\begin{array}{l}\text { CO_OPTION1 } \\
\left(Y_{50}\right)\end{array}$ & $\lambda_{y 50}=0.904$ \\
\hline & & $\begin{array}{l}\text { CO_OPTION2 } \\
\left(Y_{51}\right)\end{array}$ & $\lambda_{y 51}=0.863$ \\
\hline
\end{tabular}

The path coefficients for the structural portion of the SEM for the modified VMG model are listed in Exhibit 8. These path coefficients and their associated significance test results were used in order to evaluate the research propositions listed for Research Objective 2.

Exhibit 8: Structural portion SEM path coefficient results 


\begin{tabular}{|c|c|}
\hline SEM Path for the Modified VMG Model & Path Coefficient \\
\hline Firm Size $\left(\xi_{1}\right) \rightarrow$ Preferred Alliance Governance Mode $\left(\eta_{1}\right)$ & $\gamma_{1}=-0.078$ \\
\hline Firm Size $\left(\xi_{1}\right) \rightarrow E A V\left(\eta_{2}\right)$ & $\gamma_{2}=-0.019$ \\
\hline Competitive Position $\left(\xi_{2}\right) \rightarrow$ Resource Position $\left(\eta_{3}\right)$ & $\beta_{2}=0.963$ \\
\hline Competitive Position $\left(\xi_{2}\right) \rightarrow$ Market Position $\left(\eta_{4}\right)$ & $\beta_{3}=0.751$ \\
\hline Competitive Position $\left(\xi_{2}\right) \rightarrow$ Performance Position $\left(\eta_{5}\right)$ & $\beta_{4}=0.817$ \\
\hline Competitive Position $\left(\xi_{2}\right) \rightarrow$ Preferred Alliance Governance Mode $\left(\eta_{1}\right)$ & $\gamma_{3}=0.072$ \\
\hline Competitive Position $\left(\xi_{2}\right) \rightarrow E A V\left(\eta_{2}\right)$ & $\gamma_{4}=0.112$ \\
\hline Strategic Orientation $\left(\xi_{3}\right) \rightarrow$ Preferred Alliance Governance Mode $\left(\eta_{1}\right)$ & $\gamma_{5}=-0.130$ \\
\hline Strategic Orientation $\left(\xi_{3}\right) \rightarrow E A V\left(\eta_{2}\right)$ & $\gamma_{6}=0.246$ \\
\hline Partner Compatibility $\left(\xi_{4}\right) \rightarrow$ Cultural Compatibility $\left(\eta_{6}\right)$ & $\beta_{5}=0.691$ \\
\hline Partner Compatibility $\left(\xi_{4}\right) \rightarrow$ Operational Compatibility $\left(\eta_{7}\right)$ & $\beta_{6}=0.799$ \\
\hline Partner Compatibility $\left(\xi_{4}\right) \rightarrow$ Resource Complementarity $\left(\eta_{8}\right)$ & $\beta_{7}=0.8946$ \\
\hline Partner Compatibility $\left(\xi_{4}\right) \rightarrow$ Preferred Alliance Governance Mode $\left(\eta_{1}\right)$ & $\gamma_{7}=-0.1848$ \\
\hline Partner Compatibility $\left(\xi_{4}\right) \rightarrow E A V\left(\eta_{2}\right)$ & $\gamma_{8}=0.410$ \\
\hline $\begin{array}{l}\text { Competitive Relationship }\left(\xi_{5}\right) \rightarrow \text { Preferred Alliance Governance Mode } \\
\left(\eta_{1}\right)\end{array}$ & $\gamma_{9}=0.192$ \\
\hline Competitive Relationship $\left(\xi_{5}\right) \rightarrow E A V\left(\eta_{2}\right)$ & $\gamma_{10}=-0.059$ \\
\hline Alliance History $\left(\xi_{6}\right) \rightarrow$ Preferred Alliance Governance Mode $\left(\eta_{1}\right)$ & $\gamma_{11}=0.270$ \\
\hline Alliance History $\left(\xi_{6}\right) \rightarrow E A V\left(\eta_{2}\right)$ & $\gamma_{12}=-0.043$ \\
\hline $\begin{array}{l}\text { Perceived IPRs Regime Strength }\left(\xi_{7}\right) \rightarrow \text { Preferred Alliance Governance } \\
\text { Mode }\left(\eta_{1}\right)\end{array}$ & $\gamma_{13}=0.1687$ \\
\hline
\end{tabular}




\begin{tabular}{|l|l|}
\hline Perceived IPRs Regime Strength $\left(\xi_{7}\right) \rightarrow E A V\left(\eta_{2}\right)$ & $\gamma_{14}=0.1785$ \\
\hline$E A V\left(\eta_{2}\right) \rightarrow$ Learning $\left(\eta_{9}\right)$ & $\beta_{8}=0.649$ \\
\hline$E A V\left(\eta_{2}\right) \rightarrow$ Risk Reduction $\left(\eta_{10}\right)$ & $\beta_{9}=0.888$ \\
\hline$E A V\left(\eta_{2}\right) \rightarrow$ Vertical Integration $\left(\eta_{11}\right)$ & $\beta_{10}=0.750$ \\
\hline$E A V\left(\eta_{2}\right) \rightarrow$ Economics $\left(\eta_{12}\right)$ & $\beta_{11}=0.830$ \\
\hline$E A V\left(\eta_{2}\right) \rightarrow$ Complementarity $\left(\eta_{13}\right)$ & $\beta_{12}=0.867$ \\
\hline$E A V\left(\eta_{2}\right) \rightarrow$ Social Expansion ( $\left.\eta_{14}\right)$ & $\beta_{13}=0.490$ \\
\hline$E A V\left(\eta_{2}\right) \rightarrow$ Co-option ( $\left.\eta_{15}\right)$ & $\beta_{14}=0.733$ \\
\hline$E A V\left(\eta_{2}\right) \rightarrow$ Preferred Alliance Governance Mode $\left(\eta_{1}\right)$ & $\beta_{1}=0.1978$ \\
\hline
\end{tabular}

The results obtained by applying the Baron and Kenny (1986) process to test for the direct mediating effects of the EAV construct on the relationships between the uncertainty factors and the Preferred Alliance Governance Mode construct in the modified VMG model (Pateli, 2009) indicated the presence of mediating effects between the Preferred Alliance Governance Mode construct and each of the uncertainty factors. Moreover, in all instances the EAV construct produced partial mediation effects, except for the relationship with Competitive Position construct, which exhibited full mediation effects

\section{Reliability and Validity Test Results for Phase 2}

Similar to the reporting standard for SEM loading and path coefficient results, Vinzi, et al. (2010) suggests that the reporting of reliability and validity test results first considers the measurement portion, followed by the structural portion. The following measurement portion metrics were considered: 
- The Indicator Reliability test results revealed that the following list of reflective indicators exhibited loadings less than 0.4 during a first-run PLS regression SEM analysis:STRAT_OR4 $\left(X_{5}\right)$, MARK_POS1 $\left(Y_{11}\right)$, MARK_POS4 $\left(Y_{14}\right)$, MARK_POS4 $\left(Y_{14}\right)$, MARK_POS7 $\left(Y_{17}\right)$, OPER_COMP3 $\left(Y_{28}\right)$, VERT_INT4 $\left(Y_{42}\right)$. As a result, these unreliable reflective indicators were removed from all subsequent SEM analyses. However, all formative indicators were retained, even if their respective loadings were less than 0.4 , as was the case for PREV_DUR1 $\left(X_{9}\right)$ and LOC_OVER1 $\left(X_{6}\right)$. LOC_OVER1 showed a particularly poor performance as a formative indicator of the latent construct Competitive Relationship, which is potentially attributable to fact that the majority of respondents exhibited perfect location overlap with the research council, as their firms are also based in South Africa.

- Construct Reliability tests considered both the classic Cronbach's Alpha metric and the more contemporary Composite Reliability measure. This study's final judgment on the adequacy of a set of reflective indicators to jointly measure their related latent construct, was based on the requirement that the Composite Reliability measure needs to exceed a minimum level of 0.6 (Vinzi, et al., 2010). All sets of reflective indicators associated with latent constructs complied with this requirement.

- Convergent Reliability, which was determined through the AVE metric, measured the variance of each latent constructs reflective indicators, as captured by the construct itself, relative to the total measured variance. Measured against the study's elected threshold value of 0.5 for this metric, it could be concluded that only the Resource Position latent construct's set of reflective indicators exhibited an insufficient AVE level, indicating that, for this construct, more of the total variance measured was due to measurement error than due to indicator variance. As such, the results obtained relating to this construct cannot be viewed as valid. 
- An investigation of the Discriminant Validity results for the SEM of the modified VMG model highlighted that all latent constructs complied with the necessary requirement that the square root of each latent construct's AVE exceeds its correlation with all other latent constructs. From the Path Coefficient test results, obtained using SmartPLS's bootstrapping function configured for a resampling size of 1000 , it is clear that the following paths exhibited $p$-values (calculated using the asymptotic $t$ statistic distribution $t_{(999)}$ ) larger the maximum acceptable significance level of $\alpha=$ 0.10 , and were therefore deemed insignificant: Firm Size $\left(\xi_{1}\right) \rightarrow$ Preferred Alliance Governance Mode $\left(\eta_{1}\right)$, Firm Size $\left(\xi_{1}\right) \rightarrow \operatorname{EAV}\left(\eta_{2}\right)$, Competitive Position $\left(\xi_{2}\right) \rightarrow$ Performance Position $\left(\eta_{5}\right)$, Competitive Position $\left(\xi_{2}\right) \rightarrow$ EAV $\left(\eta_{2}\right)$, Strategic Orientation $\left(\xi_{3}\right) \rightarrow$ Preferred Alliance Governance Mode $\left(\eta_{1}\right)$, Competitive Relationship $\left(\xi_{5}\right) \rightarrow$ EAV $\left(\eta_{2}\right)$, Alliance History $\left(\xi_{6}\right) \rightarrow$ EAV $\left(\eta_{2}\right)$ and Perceived IPRs Regime Strength $\left(\xi_{7}\right) \rightarrow \operatorname{EAV}\left(\eta_{2}\right)$

The following structural portion metrics were considered:

- The Coefficients of Determination test results revealed that all of the interrelationships between the endogenous latent constructs and their related latent constructs produced explained variances exceeding the minimum level of $10 \%$. Moreover, the interrelationships with the following endogenous latent constructs were deemed to be strong, since the $R^{2}$ for these constructs exceeded 0.7: Resource Position $\left(\eta_{3}\right)$, Resource Complementarity $\left(\eta_{8}\right)$, Risk Reduction $\left(\eta_{10}\right)$ and Complementarity $\left(\eta_{13}\right)$. Interrelationships with the following endogenous latent constructs were viewed as weak, since the $R^{2}$ for these constructs were lower than 0.3: Preferred Alliance Governance Mode $\left(\eta_{1}\right)$ and Social Expansion $\left(\eta_{14}\right)$.

- A review of the Predicative Validity test results revealed that both Cross-validated Communality $\left(H^{2}\right)$ and Cross-validated Redundancy $\left(F^{2}\right)$ tested positively, indicating 
that the SEM for the modified VMG model (Pateli, 2009) is capable of, from both measurement and structural perspectives, successfully predicting governance mode decisions for research alliances with South African publicly financed R\&D organisations.

\section{Evaluation of Research Proposition 2.1}

Proposition H2.1(a)'s hypothesised relationship was rejected, since not only did the path coefficient of $\gamma_{1}=-0.078$ not support the direction of the proposed relationship, but it was also judged as not significant at the maximum allowed significance level of $\alpha=0.10$. Although the results supported the existence of partial mediation effects, Proposition H2.1(b)'s hypothesised mediating effect of the EAV construct on this relationship was rejected, due to the rejection of Research Proposition H2.1(a) (Pateli, 2009). These results challenge the findings of Pateli (2009) and oppose the reasoning of several researchers, including Leiblein and Miller (2003), Osborn and Baughn (1990), as well as Tether (2002). These researchers postulated that larger firms prefer quasi-hierarchy alliances, based on the RBV logic that more hierarchal alliances allow for the exploitation of power over resources. However, from this study's results one can argue that, according to the ROA perspective smaller R\&D firms could indicate preference for quasi-hierarchy alliance governance modes, as this could produce options for faster growth (for example, by leveraging the publicly financed R\&D partner's brand) (Leiblein, 2003). Also, from an RBV perspective, the capital intensive nature of $R \& D$ could entice small firms to seek quasi-hierarchy partnerships with larger publicly financed $R \& D$ firms that have already invested in costly resources.

\section{Evaluation of Research Proposition 2.2}

Since the path coefficient of $\gamma_{3}=0.072$ support the direction of the proposed relationship, and was also judged to be significant at the maximum allowed significance level of $\alpha=0.10$, 
proposition H2.2(a)'s hypothesised relationship could not be rejected. Also, proposition H2.2(b)'s hypothesised mediating effect of the EAV construct on this relationship could not be rejected, since the results supported the existence of full mediation effects. Although these findings contradict those of Pateli (2009), they are supported by several researchers. For example, Day and Wensley (1988) stated that the competitive position of a firm is partially determined by its resource position. Based on an RBV perspective firms wishing to maintain or achieve a competitive advantage in an environment where the rate of technological change is rapid, time-to-market and timing is critical and the nature of future competition is difficult to determine, will prefer quasi-hierarchy alliances (Hemphill and Vonortas, 2003). The need to not only acquire new competitive competencies through learning, but also protect current competitive skills and resources, drives this preference (Hemphill and Vonortas, 2003; Hamel and Prahalad, 1994). It is also motivated by an ROA perspective that obtaining such competitive competencies will create options for future growth.

\section{Evaluation of Research Proposition 2.3}

Proposition H2.3(a)'s hypothesised relationship was rejected, since not only did the path coefficient $\gamma_{5}=-0.130$ not support the direction of the proposed relationship, but it was also judged as not significant at the maximum allowed significance level of $\alpha=0.10$. Hence, while the results supported the existence of partial mediation effects, H2.3(b)'s hypothesised mediating effect of the EAV construct on this relationship could was rejected. Based on Pateli's (2009) findings the hypothesised positive relationship between the preference for quasi-hierarchy governance modes and the increased importance of growth strategies (diversification and integration) could not be rejected. This study, however, revealed that the hypothesised relationship (and any mediation effects due to the EAV) has to be rejected within the context of research alliances with South African publicly financed R\&D organisations. This seems to contradict the ROA perspective promoted by Ansoff (1965) and 
Kotler (2000) that alliance creation is sometimes viewed as option for growth, which allows for rapid service/product diversification and integration. It also challenges TCE and RBV perspectives that promote growth strategies, obtained through more hierarchical governance modes, as a vehicle to ensure cost effective safeguarding of the resources shared by the alliance (Pateli, 2009). A plausible explanation for these controversial findings could be based on the temporal context of this study: The global financial crisis, which started in 2007 due to a liquidity shortfall in the US banking system, forced many firms in countries that experienced mild recessions, such as South Africa, to downsize aggressive diversification and expansion strategies (Orr, 2010). With the median of the responses captured for measurement indicators STRAT_OR1 to STRAT_OR4 ranging from 4.0 to 5.5, this seems to also be the case for the Phase 2 respondents. Furthermore, these respondents' preference for quasihierarchy governance modes for research alliances with South African publicly financed R\&D organisations could be indicative of expectations for improved economic conditions, driven by the ROA perspective's option for future growth through partnering (Leiblein, 2003).

\section{Evaluation of Research Proposition 2.4}

Since the path coefficient of $\gamma_{7}=-0.1848$ did not support the direction of the proposed relationship hypothesised relationship of Proposition H2.4(a) was rejected, even though the path coefficient was judged as significant at the maximum allowed significance level of $\alpha=$ 0.10. The hypothesised mediating effect of the EAV construct on this relationship, as defined by Proposition H2.4(b), was rejected due to the rejection of Research Proposition H2.4(a) (Pateli, 2009), even though the existence of partial mediation effects was supported by the results. These findings oppose the TCE perspective that the coordination costs inherent in alliance management decreases if the compatibility in partners' cultures and operational strategies increase, resulting in a preference for quasi-hierarchies (Gulati and Singh, 1998). It 
also contests the RBV perspective that a preference for quasi-hierarchies results from the increased availability of complementary resources (Pateli, 2009). However, from an ROA perspective dissimilarity between alliance partners can be viewed as a source of diversity (Parkhe, 1991), which can be a powerful driver of innovation (Hamel and Prahalad, 1994).

\section{Evaluation of Research Proposition 2.5}

Proposition H2.5(a)'s hypothesised relationship could not be rejected, since not only did the path coefficient of $\gamma_{9}=0.192$ support the direction of the proposed relationship, but it was also judged to be significant at the maximum allowed significance level of $\alpha=0.10$. Furthermore, since the results supported the existence of partial mediation effects, H2.5(b)'s hypothesised mediating effect of the EAV construct on this relationship could not be rejected. These findings support Kogut's (1988) notion that quasi-hierarchies are preferred in highly competitive alliances, since the RBV perspective suggests that these structures provide protection to induce knowledge sharing, while the TCE perspective advocates that it allows partners to sustain their own core competencies. The observed mediation effects can be explained from an ROA perspective: Competitive relationships in emerging industries are characterised by the phenomenon of information asymmetry (Pateli, 2009). Players in such

markets aspire to increase their knowledge of the competition, the technologies allowing them to compete in the market, the risks inherent in the market, and customer demand (Pateli, 2009). This knowledge allows firms to differentiate themselves in such emerging markets (Pateli, 2009). Thus, even though R\&D firms view certain research alliance partners as competition, the option for growth resulting from the potential detection of complementary resources and skills at these partners could increase the EAV, followed by an increase in the attractiveness of quasi-hierarchy governance modes (Pateli, 2009). 
Not only was the path coefficient of $\gamma_{11}=0.270$ judged to be significant at the maximum allowed significance level of $\alpha=0.10$, but it also supported the direction of the proposed relationship. Hence, Proposition H2.6(a)'s hypothesised relationship could not be rejected. Proposition H2.6(b)'s hypothesised mediating effect of the EAV construct on this relationship could also not be rejected, since the results supported the existence of partial mediation effects. These findings can be explained from an ROA perspective: Increased levels of trust are created through mutual experiences in research alliances, leading to decreased uncertainty and positive expectations of partner behaviour (Gulati, 1995). This increased level of trust will enhance the preference for quasi-hierarchies, as the decrease in partner uncertainty encourages partners to commit more resources to create options for future growth (Pateli, 2009).

\section{Evaluation of Research Proposition 2.7}

Proposition 2.7(a)'s hypothesised relationship could not be rejected, since not only did the path coefficient of $\gamma_{13}=0.1687$ support the direction of the proposed relationship, but it was also judged to be significant at the maximum allowed significance level of $\alpha=0.10$. Since the results supported the existence of partial mediation effects, Proposition H2.7(b)'s hypothesised mediating effect of the EAV construct on this relationship could not be rejected. Furthermore, the three impact domains related to the Acts, identified during Phase 1, proved to be useful as formative indicators in the SEM of the modified VMG model for the Perceived IPRs Regime Strength (Oxley, 1999) external uncertainty factor, since these indicators' loadings, $\pi_{x 6}=0.779, \pi_{x 7}=0.591$ and $\pi_{x 8}=0.906$, were substantial. The preference for quasi-hierarchy governance modes for research alliances with South African publicly financed R\&D organisations could be attributed to an RBV perspective that a strong IPRs regime will ensure the protection of the IPRs assets created and owned by the alliance. Furthermore, from an ROA perspective, the IPRPFRD Act's (Republic of South Africa, 
2008a) resolute requirement that all IP generated from publicly financed R\&D needs to be commercialised, can be viewed as an option for growth, although somewhat forced.

\section{Evaluation of Research Proposition 2.8}

Since the path coefficient of $\beta_{1}=0.1978$ support the direction of the proposed relationship, and it was also judged to be significant at the maximum allowed significance level of $\alpha=$ 0.10, Proposition H2.8's hypothesised relationship could not be rejected. Although this conforms to Pateli's (2009) assertion that EAV is a significant determinant of the governance mode choice, it did not support Patel's findings that quasi-market alliances will be preferred in cases of high expectations for the alliance value. As such, one could argue that the ROA perspective that the options for growth resulting from the creation of equity alliances (Ansoff, 1965; Kotler, 2000) outweighed the counter perspective that the ability to delay or defer irreversible investment in such equity alliances under high exogenous uncertainty can produce managerial flexibility (Leiblein, 2003; McDonald and Siegel, 1986).

\section{CONCLUSIONS}

Phase 1 of this study determined that seven of the eight original business impact domains identified by Baloyi, et al. (2009) as areas in the new legislative framework that could influence operations, infrastructure and resources at the research council in general, were regard as potential impact domains that could either positively or negatively impact research alliances with publicly financed R\&D organisations. A further six additional impact domains that were not previously identified by Baloyi, et al. (2009), were also discovered. The 13 potential impact domains identified during Phase 1 were then ranked in terms of their relative severity levels using a weighted frequency analysis. Exhbit T4 summarises the ranked list of impact domains identified in the Acts, as well as the speculated nature of their influences on 
research alliances' preference to choose quasi-hierarchy governance modes. The economic driver for each impact domain is also given.

Exhibit 9: Summary of the main findings of Phase 1

\begin{tabular}{|c|c|c|}
\hline Impact Domain (with Ranking) & $\begin{array}{l}\text { Nature of the Potential } \\
\text { Influence on the } \\
\text { Preference for Quasi- } \\
\text { Hierarchies }\end{array}$ & $\begin{array}{l}\text { Driver(s) of } \\
\text { the Expected } \\
\text { Influence }\end{array}$ \\
\hline \multirow[t]{2}{*}{ Choice of IPRs Ownership (Ranked $1^{\text {st }}$ ) } & Positive & $T C E$ \\
\hline & Negative & $R O A$ \\
\hline \multirow{2}{*}{$\begin{array}{l}\text { State Walk-in Rights on IP not Declared } \\
\left(\text { Ranked } 1^{\text {st }}\right) \text { : }\end{array}$} & Positive & $R O A$ \\
\hline & Negative & $R O A$ \\
\hline Benefit Sharing Policies (Ranked $2^{\text {nd }}$ ) & Positive & $R B V$ \\
\hline $\begin{array}{l}\text { Requirement to Register IP in the OpenSource } \\
\text { Software Community (Ranked } 3^{\text {rd }} \text { ) }\end{array}$ & Negative & $\begin{array}{l}\text { TCE and } \\
R O A\end{array}$ \\
\hline Offshore IP Registration Process (Ranked $4^{\text {th }}$ ) & Negative & $T C E$ \\
\hline $\begin{array}{l}\text { Requirement for Non-exclusivity in IP } \\
\text { Transactions (Ranked } 5^{\text {th }} \text { ) }\end{array}$ & Negative & $\begin{array}{l}\text { TCE and } \\
R O A\end{array}$ \\
\hline \multirow{2}{*}{$\begin{array}{l}\text { Preference in Commercialisation Rights to } \\
\text { SMEs and Broad Based Black Economic } \\
\text { Empowerment (BBBEE) Firms (Ranked } 5^{\text {th }} \text { ) }\end{array}$} & Negative & $R O A$ \\
\hline & Positive & $R B V$ \\
\hline \multirow[t]{2}{*}{ IP Detection Process (Ranked $6^{\text {th }}$ ) } & Positive & $T C E$ \\
\hline & Negative & $T C E$ \\
\hline
\end{tabular}




\begin{tabular}{|l|l|l|}
\hline Government Reporting Process $\left(\right.$ Ranked $^{\text {th }}$ ) & Negative & TCE \\
\hline Government Reaction Time (Ranked $7^{\text {th }}$ ) & Negative & TCE \\
\hline IP Declaration Process (Ranked $8^{\text {th }}$ ) & Negative & RCE and \\
\hline $\begin{array}{l}\text { Structural and Resource Requirements (Ranked } \\
9^{\text {th }} \text { ) Negative }\end{array}$ & RCE and \\
\hline Unclear Guidelines for the TIA Funding of & Negative & RBV \\
Innovations (Ranked $9^{\text {th }}$ ) & & \\
\hline
\end{tabular}

Exhibit 9 demonstrates that the expected impact that the identified domains will have on research alliances' preference for quasi-hierarchies is primarily rooted in TCE's cost savings perspective. This TCE driver is followed by ROA's managerial flexibility perspective, with RBV's shared resource leveraging perspective acting is the least significant driver. Hence, it can be concluded that the additional administrative and operational costs resulting from, for example, the creation and policing of complex contractual agreements for research alliances with publicly financed $R \& D$ organisations are the primary disincentives for the selection of quasi-hierarchy governance modes for such alliances that operate within Bayh-Dole-like IPRs legislative regimes.

Phase 2 revealed that the Firm Size, Strategic Orientation and Partner Compatibility uncertainty factors included in the original VMG model proposed by Pateli (2009) did not significantly influence the governance mode preference for research alliances with South African publicly financed R\&D organisations. Exhibit 10, which summarises these results, also shows the relationships with the remaining uncertainty factors that were not rejected all exhibited mediation effects via the EAV construct. Also included in Exhibit 10 are the 
suggested drivers (TCE, RBV or ROA) behind the findings related to the relationships between the uncertainty factors and the preferred alliance governance mode.

The findings of five of the seven proposed relationships between uncertainty factors and the governance mode preference could, in part, be explained using argumentation based on ROA perspectives. It can therefore be concluded that there is validity in Pateli's (2009) claim that many theoretical models for the governance mode decision making of alliances, such as the models by Parkhe (1993) and Leiblein (2003), not only have an over reliance on opportunism-based TCE perspectives, but completely neglect the value-related aspects of the alliance, embodied by ROA perspectives.

Exhibit 10: Summary of the main findings of Phase 2

\begin{tabular}{|l|l|l|}
\hline Factor) & Judgement on the Relationship with the & Driver(s) for \\
& Preferred Alliance Governance Mode & the Judgement \\
\hline Firm Size (Internal) & Rejected & ROA and \\
& & RBV \\
\hline Competitive Position (Internal) & Not Rejected, Fully Mediated by EAV & ROA and \\
\hline Strategic Orientation (Internal) & Rejected & RBV \\
\hline Partner Compatibility (Internal) & Rejected & ROA \\
\hline Competitive Relationship & Not Rejected, Partial Mediation by & ROA, RBV, \\
(External) & EAV & TCE \\
\hline Alliance History (Internal) & Not Rejected, Partial Mediation by & ROA \\
\hline
\end{tabular}




\begin{tabular}{|l|l|l|}
\hline Perceived IPRs Regime Strength & Not Rejected, Partial Mediation by & ROA and \\
(External) & EAV & RBV \\
\hline
\end{tabular}

The Perceived IPRs Regime Strength external uncertainty factor that was added to Pateli's (2009) original VMG model during Phase 2, proved to be a significant predictor for the preferred alliance governance mode of research alliances. It was also conclusively shown that the relationship that this external uncertainty factor has with the preference for quasihierarchies is partially mediated by the EAV. The choice of IPRs ownership, state walk-in rights on undeclared IP and benefit-sharing policies proved to be significant formative indicators for the Perceived IPRs Regime Strength construct that contributed positively to the perceived IPRs regime strength.

Future research will include exploring the potential use of the Perceived IPRs Regime Strength within a framework for technology forecasting through SEM base data fusion. In this framework the IPR Regime Strength will be employed as context related model construct.

\section{REFERENCES}

Abdi, H., (2010), Partial Least Squares Regression and Projection on Latent Structure Regression (PLS-Regression). Wiley Interdisciplinary Reviews: Computational Statistics, 2, 97-106.

Ansoff, H.I., (1965), Corporate Strategy. New York: McGraw-Hill.

Baloyi, J., De Jager, P., Debba, P., Kotze, L., Lehmann, J., Mabuse, M., Mophuti, L., Msimang, N., Nel, W.A.J., Ngwato, P., Ntene, T., Sithole, H., Skosana, S., Steenkamp, K., Swartbooi, A., Tshikomba, J., Van der Merwe, C., Weerts, S., Wise, R. and Woodborne, M., 
(2009), The TIA and the IPR Acts: Implications for the CSIR (CSIR SLP03 Report). ftp://ftp.csir.co.za/RD/CiLLA/SLP0309/GroupAssign-ment [1 April 2010].

Baron, R.M. and Kenny, D.A., (1986), The Moderator-Mediator Variable Distinction in Social Psychological Research: Conceptual, Strategic and Statistical Considerations. Journal of Personality and Social Psychology, 51, 1173-1182.

Chen, H. and Chen, T.J., (2003), Governance Structures in Strategic Alliances: Transaction Costs versus Resource-Based Perspective. Journal of World Business, 38(1), 1-14.

Clandinin, D.J. and Connelly, F.M., (2000), Narrative Inquiry: Experience and Story in Qualitative Research. San Francisco: Jossey-Bass Publishers.

Day, G.S. and Wensley, R., (1988), Assessing Advantage: A Framework for Diagnosing Competitive Advantage. Journal of Marketing, 52, 1-20.

Dinopoulos, E., \& Segerstrom, P., (2010), Intellectual Property Rights, Multinational Firms and Economic Growth. Journal of Development Economics, 92(1), 13-27.

Glasser, B., (1965), The Constant Comparative Method of Qualitative Analysis. Social Problems, 12(4). California: University of California Press.

Goodhue, D., Lewis, W. and Thompson, R., (2006), PLS, Small Sample Size, and Statistical Power in MIS Research, IEEE Proceedings of the 39th Hawaii International Conference on System Sciences.

Google, (2010), Google Forms Help Website. http://docs.google.com/support/bin/answer.py? hl=en\&answer=87809 [17 August 2010].

Guest, G., Bunce, A. and Johnson, L., (2006), How Many Interviews Are Enough? An Experiment with Data Saturation and Variability. Field Methods, 18(59), 59-82. 
Guion, L.A., (2002), Triangulation: Establishing the Validity of Qualitative Studies. FCS6014. Department of Family, Youth and Community Science, Florida Cooperative Extension Service, Institute of Food and Agricultural Science, University of Florida.

Gulati, R., (1995), Social Structure and Alliance Formation Patterns: A Longitudinal Analysis. Administrative Science Quarterly, 40(4), 619-52.

Gulati, R. and Singh, H., (1998), The Architecture of Cooperation: Managing Coordination Costs and Appropriation Concerns in Strategic Alliances. Administrative Science Quarterly, 43(4), 781-814.

Haenlein, M. and Kaplan, A.M., (2004), A Beginner's Guide to Partial Least Squares Analysis. Understanding Statistics, 3(4), 283-297.

Hagedoorn, J., Cloodt, D. and van Kranenburg, H., (2005), Intellectual Property Rights and the Governance of International R\&D Partnerships. Journal of International Business Studies, Palgrave Macmillan Journals, 36(2), 175-186.

Hamel, G. and Prahalad, C.K., (1994), Competing for the Future. Boston, Massachusetts: Harvard Business School Press.

Hemphill, T.A. and Vonortas, N., (2003), Strategic Research Partnerships: A Managerial Perspective. Technology Analysis and Strategic Management, 15(2), 255-71.

Hertzfeld, H.R., Link, A.N. and Vonortas, N.S., (2001), Research Partnerships and Intellectual Property: Literature Review. Mimeograph. Centre for International Science and Technology Policy, George Washington University and Bryan School of Business and Economics, University of North Carolina at Greensboro.

Hertzfeld, H.R., Link, A.N. and Vonortas, N.S., (2006), Intellectual Property Protection Mechanisms in Research Partnerships. Research Policy, Elsevier, 35(6), 825-838. 
Howarth, C.S., (1994), The Role of Strategic Alliances in the Development of Technology. Technovation, 14(4), 243-257.

Kogut, B., (1988), Joint Ventures: Theoretical and Empirical Perspectives. Strategic Management Journal, 9(4), 319-32.

Kotabe, M. and Swan, K.S., (1995), The Role of Strategic Alliances in High-Technology New Product Development. Strategic Management Journal, 16(8), 621-636.

Kotler, P., (2000), Marketing Management. 10th ed., Englewood Cliffs, NJ: Prentice-Hall. Leiblein, M.J., (2003), The Choice of Organizational Governance Form and Firm Performance: Predictions from Transaction Cost, Resource-based, and Real Option Theories. Journal of Management, 29(6), 937-962.

McDonald, R. and Siegel, D., (1986), The Value of Waiting to Invest. Quarterly Journal of Economics, 101(4), 707-727.

Maredia, M.K., (2001), Application of Intellectual Property Rights in Developing Countries: Implications for Public Policy and Agricultural Research Institutes. Final Draft Submitted to the World Intellectual Property Organization. http://www.wipo.int/export/sites/www/aboutip/en/studies/pdf/study_k_maredia.pdf [2 April 2010].

Mowery, D.C. and Sampat, B.N., (2005), The Bayh-Dole Act of 1980 and UniversityIndustry Technology Transfer: A Model for Other OECD Governments? Journal of Technology Transfer, 30 (1/2), 115-127.

Narula, R. and Hagedoorn, J., (1999), Innovating through Strategic Alliances: Moving towards International Partnerships and Contractual Agreements. Technovation, 19(5), 283294. 
OECD, (2003), Turning science into business: Patenting and Licensing at Public Research Organisations. http://www.oecd.org/publishing [2 April 2010].

Orr, S., (2010), Post Global Financial Crisis International Business Strategies. International Review of Business Research Papers, 6(4), 324-336.

Osborn, R.N. and Baughn, C.C., (1990), Forms of Interorganizational Governance for Multinational Alliances. Academy of Management Journal, 33(3), 503-19.

Oxley, J.E., (1999), Institutional Environment and the Mechanisms of Governance: The Impact of Intellectual Property Protection on the Structure of Inter-Firm alliances. Journal of Economic Behavior and Organization, 38(1999), 283-309.

Oxley, J.E. and Sampson, R.C., (2004), The Scope and Governance of International R\&D Alliances. Strategic Management Journal, 25(8/9), 723-749.

Parkhe, A., (1991), Interfirm Diversity, Organizational Learning and Longevity in Global Strategic Alliances. Journal of International Business Studies, 22(4), 579-601.

Parkhe, A., (1993), Strategic Alliance Structuring: A Game Theoretic and Transaction Cost Examination of Interfirm Cooperation. The Academy of Management Journal, 36(4), 794829.

Pateli, A.G., (2009), Decision Making on Governance of Strategic Technology Alliances. Management Decision, 47(2), 246-270.

Republic of South Africa, (2008a), Intellectual Property Rights from Publicly Financed Research and Development Act. http://www.info.gov.za/view/DownloadFileAction?id= 94343 [2 April 2010].

Republic of South Africa, (2008b), Technology Innovation Agency Act. http://www.info.gov.za/view/ DownloadFileAction?id=92827 [2 April 2010]. 
Ringle, C.M., Wende, S. and Will, S., (2010), SmartPLS 2.0. http://www.smartpls.de/forum/ downloads.php [2 October 2010].

So, A.D., Sampat, B.N., Rai, A.K., Cook-Deegan, R., Reichman, J.H., Weissman, R. and Kapczynski, A., (2008), Is Bayh-Dole Good for Developing Countries? Lessons from the US Experience. PLoS Biology, 6(10), 2078-2084.

Tether, B., (2002), Who Co-operates for Innovation, and why? An Empirical Analysis. Research Policy, 35(6), 947-67.

Vinzi, V.E., Chin, W.W., Henseler, J. and Wang, H., (2010), Handbook of Partial Least squares: Concepts, Methods and Applications. Berlin Heidelberg: Springer.

Wang, E.T.G. and Wei, H-L., (2007), Interorganizational Governance Value Creation: Coordinating for Information Visibility and Flexibility in Supply Chains. Decision Sciences, $38(4), 647-674$.

Zikmund, W., (2003), Business Research Methods, 7th Edition. Ohio: South-Western Cengage Learning. 